\title{
“We Missed Caparica": a Experiência Educativa do Estrangeiro em The Young Traveller in Portugal [1955] ${ }^{1}$
}

Maria Zulmira Castanheira

FCSH-UNL/CETAPS

\begin{abstract}
m 1947, no pós-Segunda Guerra Mundial, quando se começou a assistir a um enorme desenvolvimento da prática turística, a editora londrina Phoenix House lançou uma colecção ilustrada com o título "The Young Traveller Series". Ao primeiro volume, dedicado à África do Sul, seguir-se-iam outros quarenta, destinados à faixa etária dos doze aos dezasseis anos. Bem recebidos por pais e professores, passaram a integrar as listas das leituras aprovadas e recomendadas por muitas instituições, nomeadamente a Library Association, a School Library Association e a National Book League. O objectivo era descrever a vida de vários países, expondo os jovens leitores à diversidade do mundo e à diferença linguística $\mathrm{e}$ cultural. Os testemunhos que encontramos hoje na Internet de pessoas que recordam o muito que apreciaram na infância ou adolescência tais obras, e o quanto elas os motivaram para o acto de viajar, dão-nos alguma ideia da influência que a colecção exerceu.
\end{abstract}

1. O presente artigo é uma versão bastante modificada e expandida da comunicação que apresentei na Conferência Internacional Youth in/and Literature \& Society, 9-11 Julho 2014, Faculdade de Ciências Sociais e Humanas da Universidade Nova de Lisboa, Portugal. Trata-se de um estudo realizado no âmbito do grupo de investigação "Anglo-Portuguese Studies" do CETAPS (Centre for English, Translation and Anglo-Portuguese Studies, projecto UID/ELT/04097/2013), unidade de investigação avaliada e financiada pela FCT-Fundação para a Ciência e a Tecnologia, Portugal. 
Em cada volume, dois jovens passam um determinado período de tempo num país estrangeiro, umas vezes com familiares, outras vezes na companhia de outras pessoas; o facto de se tratar de um rapaz e de uma rapariga potenciava o interesse do público, na medida em que os livros poderiam agradar a leitores de ambos os sexos. Fugindo às convenções mais áridas do livro de viagens (nomeadamente a profusão de informação objectiva, prática, utilitária), a colecção adoptou um método atraente e eficaz de apresentar o Outro ao público infantil e juvenil, publicando narrativas plenas de acção protagonizadas por crianças e jovens que passavam pela experiência de entrar em contacto com as mais diversas regiões do globo. Em 1954, em virtude do fascínio da época pelas viagens espaciais, a colecção abriu-se excepcionalmente ao mundo extraterrestre, tendo então sido publicado o volume The Young Traveller in Space, do conhecido autor de ficção científica Arthur C. Clarke (1917-2008).

No ano seguinte, 1955, quando tinham já sido dados à estampa volumes sobre mais de vinte países diferentes, de todos os continentes, foi publicado um dedicado a Portugal: The Young Traveller in Portugal, da jornalista Honor Wyatt (1910-1998). ${ }^{2}$ Nos Agradecimentos ("Acknowledgments"), a autora afirma: "This is a book of fiction based on fact. Any resemblance of the characters to actual persons is most understandable." (Wyatt: 10) Estas palavras tornam explícito o quanto a escrita de viagem - que nas últimas décadas tem despertado grande interesse e conquistado o respeito da academia e da crítica - se move num terreno instável, entre a verdade e a ficção, e combina as dimensões subjectiva e objectiva: "travel writing enjoys an intermediary status between subjective inquiry and objective documentation". (Holland e Huggan: 11) Género frequentemente sob suspeita, por se desconfiar da veracidade do narrador, nomeadamente quando este se afasta muito do que é conhecido/familiar, são por isso muitos os autores de livros de viagens que têm a preocupação de

2. Honor Wyatt foi uma jornalista que trabalhou para a BBC e depois como freelancer. O seu filho mais velho, Julian (Adrian, na obra em análise), é fruto do seu primeiro casamento com o também jornalista Gordon Glover, e os mais novos, Prudence e Robert, que em The Young Traveller in Portugal recebem os nomes nomes fictícios de Patience e William, do seu segundo casamento com George Ellidge, psicólogo industrial, falecido em 1969. 
reivindicar para os seus testemunhos um estatuto de autenticidade; ${ }^{3}$ e o de Honor Wyatt não foge a essa prática, quando afirma, a páginas 61, que só registará aquilo que realmente aconteceu. As fotografias que acompanham o texto, outra forma de registo, concorrem para a credibilidade do relatado, comprovando a prática de documentação visual que crescentemente se foi registando na escrita de viagem após o advento daquela tecnologia da imagem. ${ }^{4}$

$\mathrm{Na}$ verdade, a narrativa tem um forte cunho autobiográfico, na medida em que se apresenta como fruto de uma viagem ao Portugal do Estado Novo realizada em 1953 pela autora na companhia do marido (George Ellidge, no texto referido pelas iniciais G.H.), um casal de ideias liberais, e dois filhos, que na obra recebem os nomes de William, de doze anos, e Patience, de quinze (os nomes verdadeiros dos filhos, Robert ${ }^{5}$ e Prudence, ${ }^{6}$ são referidos na dedicatória do livro: "For those excellent young travellers Prudence and Robert"), viagem essa feita com o propósito concreto de Honor Wyatt escrever um livro sobre Portugal.

Apesar do fim utilitário em vista (desconhecemos as circunstâncias em que foi feita a encomenda da obra), não deixa de ser uma viagem por prazer realizada por uma família que se desloca de um centro cultural, a Inglaterra, para uma periferia da Europa, Portugal, a qual se torna alvo de observação e também de comparação.

3. Adopto aqui a definição de livro de viagens proposta por Jan Borm: "any narrative characterized by a non-fiction dominant that relates (almost always) in the first person a journey or journeys that the reader supposes to have taken place in reality while assuming or pressuposing that author, narrator and principal character are but one or identical." (Borm: 17)

A definição de livro de viagens proposta por Paul Fussell ajuda também a perceber a especificidade do género: "Travel books are a sub-species of memoir in which the autobiographical narrative arises from the speaker's encounter with distant or unifamiliar data, and in which the narrative - unlike that in a novel or a romance - claims literal validity by constant reference to actuality." (Fussell: 203)

4. À semelhança das narrativas de viagem escritas na mesma época, as fotografias incluídas na obra de Honor Wyatt documentam o mundo rural (trajes regionais, tarefas agrícolas como as ceifas ou as vindimas, carros de bois), vistas urbanas panorâmicas (Estoril e Baixa Pombalina) ou pormenores de espaços urbanos considerados pitorescos (as ruas estreitas de Évora, Lisboa e Porto, com a roupa estendida às janelas e varandas), manifestações religiosas (romarias, procissões), atracções turísticas (Torre de Belém, túmulos de D. Pedro I e D. Inês de Castro, em Alcobaça, a biblioteca da Universidade de Coimbra, construções arquitetónicas ilustrativas do estilo manuelino...), paisagens costeiras (aldeia piscatória da Nazaré) e figuras típicas do povo, como os vendedores ambulantes de melões e louça de barro e os campinos.

5. Trata-se do músico Robert Wyatt, nascido em 1945, fundador da banda rock Soft Machine

6. Prudence, mais tarde Prudence Anderton, nasceu em 1939. 
Os protagonistas evidenciam entusiasmo pela constante novidade e diferença com que se deparam, revelando especial interesse pela autenticidade que encontram no mundo rural português - e que deixa depreender, da parte da narradora, uma certa nostalgia por um modo de vida pré-industrial que entretanto se perdera na sociedade de que é oriunda (ainda que tal nostalgia não conduza à expressão de uma vontade de conversão a esse mesmo modo de vida).

As férias em família, uma prática que se acentuou no pós-Segunda Guerra Mundial, estão aqui bem ilustradas, constituindo esse, aliás, um dos traços característicos dos viajantes britânicos que visitaram Portugal nas primeiras décadas da segunda metade do século XX, como concluiu Valentino José Carvalho do Vale Alves:

De facto, nos anos 50 e 60, o turista britânico que visitava Portugal pode, grosso modo, ser catalogado como um indivíduo de meia-idade, de classe média ou média-alta, culto e que viajava em família. Os seus interesses passavam por conhecer Portugal como um todo, não privilegiando grandemente regiões específicas, à excepção, talvez, de Lisboa; fruir da riqueza patrimonial arquitetónica e artística, deliciar-se com o atraso do país e com a natureza afável e ingénua do povo. Portugal era um velho aliado e, simultaneamente, um desconhecido e atractivo destino pautado pela sua natureza paradisíaca. (Alves: 115)

A circunstância de a própria escrita estar na origem da viagem, à semelhança do que sucede com outros viajantes britânicos, é recordada ao longo da obra através de referências frequentes aos apontamentos tirados, quer pela própria autora-narradora, quer pelos seus dois filhos, tendo em mente a tarefa que os move. Apesar de o eu-narrador ser a mãe, o relato é, em larga medida, sobre o que William e Patience viram, o que pensaram e como reagiram, procurando, assim, cativar mais directamente o público-alvo infanto-juvenil a que o livro se destina. Para tal concorre a estratégia narrativa adoptada pela autora de inserir no seu texto excertos de cartas escritas pelos filhos ao irmão Adrian (na realidade, Juliann ${ }^{7}$, que havia ficado em

7. Trata-se do actor de teatro, televisão e cinema Julian Glover, nascido em 1935, que participou em êxitos como Star Wars: Episode V - The Empire Strikes Back, Indiana Jones and the Last Crusade, Harry Potter and the Chamber of Secrets e, mais recentemente, na série televisiva Game of Thrones. 
Inglaterra, ou extractos do diário da filha, dando-lhes pois voz e introduzindo o seu discurso jovial, na primeira pessoa, em que descrevem pelas suas próprias palavras, por vezes com alguma incorreção gramatical, os lugares por onde passaram e os episódios que viveram. Os jovens a quem a obra se dirige são, deste modo, sensibilizados para o interesse em registar por escrito as impressões recolhidas aquando do contacto com uma realidade distinta da de origem.

Esta é apenas uma das vertentes instrutivas de uma viagem que desde o início se assume como educativa, o que a inscreve numa longa tradição. Efectivamente, não só a aquisição de conhecimentos e o alargamento de horizontes estão desde sempre associados ao acto de viajar, como a escrita de viagem, género vocacionado para a tematização e problematização da diferença cultural, integra na sua variada tipologia a viagem de formação, a qual inclui, no seu historial, o ritual ideológico do Grand Tour, marcado por aquilo a que Charles Batten (1978) chamou "pleasurable instruction." Tal prática de uma viagem pela Europa continental, destinada a completar a educação dos filhos das famílias das classes superiores, realizada normalmente após a conclusão dos estudos universitários em Oxford ou Cambridge, viria a perder força ao longo de Oitocentos, à medida que um novo paradigma da viagem, o do turismo de massas, se começava a impor. A viagem de Honor Wyatt a Portugal, na companhia da sua família, tem lugar num século em que o acto de viajar deixara de ser elitista, um privilégio apenas ao alcance de alguns, e, graças ao progresso tecnológico e económico, se democratizara e banalizara. Consequentemente, a prática da viagem sofreu profundas alterações, passando a incluir novos hábitos sociais, nomeadamente o campismo.

Em The Young Traveller in Portugal temos precisamente o exemplo de uma família inglesa que vem até Portugal fazer umas férias de vários meses com um orçamento limitado ${ }^{8}$ - o que contrasta com o tipo de viajante britânico de elevada condição económica, como as autoras de The Selective Traveller in Portugal (1949) de que falaremos adiante, que no Verão de 1947 se deslocam em carro alugado, com

8. "'The point is', G. H. explained, 'that we shall really have to camp because it will be so much cheaper. My wife is writing a book about Portugal and we intend to travel from North to South. That will take at least five weeks". (Wyatt: 12) 
chauffeur, e pernoitam em hotéis e pousadas -, optando pelo campismo e apresentando-o como uma experiência divertida e simultaneamente instrutiva, ${ }^{9}$ que os portugueses, sobretudo os jovens, também já começavam a viver, como puderam ficar a saber assim que chegaram ao Porto, vindos de Londres:

'You are going camping?'

'Yes, once we get into the country', G.H. told him. 'Will people think it rather strange, do you think?'

'Oh no! Ten years ago perhaps, but not now. Quite many people in Portugal do the camping, though more young people than adults. However, everybody will understand. After all, you are English.'

'You mean, after all we are crazy?' I suggested.

'Madam, I did not say that!' (Wyatt: 12)

Este breve diálogo, que introduz já a questão, que voltará a ser referida, das imagens estereotipadas que as nações têm umas das outras, e que podem concorrer para a falta de entendimento entre os povos - neste caso a autora alude à tão apregoada excentricidade inglesa -, apresenta o campismo como uma opção económica para viagens em família, ainda que não esteja isenta de riscos, como por exemplo o inesperado aparecimento de animais perigosos (um lobo, uma cobra). (Wyatt: 65-66, 116) ${ }^{10}$ Tais episódios, porém, são apresentados na obra como aventuras excitantes e memoráveis, que não retiram qualquer entusiasmo aos viajantes. No texto da badana da sobrecapa de The Young Traveller in Portugal, onde se faz publicidade a Portugal e se procura motivar os jovens a visitá-lo, pode ler-se: "A camping holiday is fun at any time, but how much more so when it is spent abroad! William and Patience felt they really knew the friendly Portuguese after several months of camping on beaches, on moun-

9. Matthew de Abaitua sublinha o carácter educativo do campismo e fornece uma contextualização histórica desta prática, cujas origens faz remontar à Roma Antiga: "The educational role of camping goes all the way back to the Campus Martius of Rome, the martial field where soldiers trained and games were held, and continues today in the 'campus' grounds of universities." (Abaitua: 17)

10. Numa outra obra de Honor Wyatt, a que farei referência no final do artigo, a autora alerta para a facto de não ser aconselhável que os jovens façam campismo no estrangeiro sem acompanhamento de adultos: "It is extremely unwise for young people to camp on their own in foreign countries." (Wyatt, 1961: 124) 
tain sides, in cottages and tiny chalets all over Portugal." Habituados a outros confortos, a simplicidade da vida ao ar livre - comer com as mãos, lavar a loiça no mar, enterrar o lixo na areia - leva os jovens protagonistas a interrogar-se sobre o supérfluo da civilização: "The children wondered, with sorrow, why civilization ever went to the trouble of inventing table-linen and cutlery." (Wyatt: 138) Michel Butor, no seu conhecido ensaio "Travel and Writing", ao traçar uma tipologia da viagem, atribui à viagem de férias e, nomeadamente, à experiência do campismo, uma dimensão teatral, na medida em que constitui um temporário "faz-de-conta": "(...) travel can become theater. We mimic another trip, change houses for a while, settle elsewhere briefly, seek a new region to live, play at emigrating, at wandering; thus, we go camping and return to a tent or the open, starry skies; for a short time we have no fixed residence." (Butor: 76) Para os próprios adultos acampar possuía também uma vertente lúdica, ao permitir a fuga à rotina e à pressão do quotidiano citadino.${ }^{11}$ Além disso, a proximidade que este tipo de férias impunha tinha o potencial de promover a união entre os membros da família - não há quaisquer tensões entre os jovens protagonistas de The Young Traveller in Portugal e seus pais, reinando a harmonia e a boa disposição -, um aspecto realçado por Orvar Löfgren no capítulo intitulado "On the Move" da sua obra On Holiday: A History of Vacationing: "Learning to be a tourist, experiencing exotic places and strange foods often occurred within the framework of 'the family vacation' and the family car. This mode of traveling became an instruction in how to be a family. The close living, the common project of vacationing developed new forms of togetherness". (Löfgren: 63)

Publicado num período em que a escrita de viagem se tornava cada vez menos didáctica e cada vez mais subjectiva e impressionista - libertada já dos constrangimentos das viagens de tempos idos, feitas por pura necessidade e marcadas por provações de natureza vária,

11. For adults, camping offers not a break from work but a different type of work. Simple minor tasks, such as pitching a tent or setting the campfire, which have instant and tangible rewards, take precedence over the complex, abstract or deskilled work of town and city. Beneath this seemingly innocuous recreational pursuit lies a drawing apart from the mediated, passive, mortgaged, stressed lot of contemporary life. To its believers, camping is freedom; to its detractors, it represents a perverse nostalgia for the prison of nature that mankind spent millenia trying to escape. (Abaitua: 18) 
para se tornar crescentemente uma prática voluntária e de lazer -, The Young Traveller in Portugal apresenta, contudo, um forte didactismo, dados os propósitos da colecção em que se insere. Ao longo do percurso efectuado em terras portuguesas, viajando de Norte para Sul "along the road of history", (Wyatt: 76) os pais vão dando aos filhos lições sobre a História de Portugal (lugares, edifícios, personagens como D. Pedro e D. Inês de Castro, o Infante D. Henrique, etc.), explicam o modo de fabrico de determinados produtos (por exemplo, o vinho do Porto) (Wyatt: 25-29) ou o funcionamento de certos mecanismos (como uma nora), (Wyatt: 57) e procuram proporcionar-lhes a possibilidade de ver fábricas (de conservas, de cortiça), (Wyatt: 113, 120) assistir a uma romaria, visitar o santuário de Fátima e monumentos como os mosteiros de Alcobaça e da Batalha (os quais, contudo, não são descritos em pormenor, pois as referências a estas construções surgem como tendo sido reproduzidas das páginas do diário de Patience e não seria de esperar de uma jovem o mesmo tipo de descrição que um adulto faria), tendo em vista a sua formação. Mas, significativamente, não foram ver uma tourada, pois tal experiência não é considerada educativa: " 'When shall we go to a bullfight?' William wanted to know. He was told 'not at all'. For two reasons. One: children are not allowed. Two: neither Patience nor William would enjoy seeing the bull baited, even though the bull is not killed in Portugal, as it is in Spain." (Wyatt: 66) Repetem-se ao longo do texto expressões como "for the sake of your education", (Wyatt: 15) "very educational", (Wyatt: 71) "for educational reasons", (Wyatt: 112) expressões estas que condensam as traves-mestras da construção do discurso que compõe The Young Traveller in Portugal. Apesar do estilo leve e de algum humor, a obra revela uma preocupação: a de que a literatura dirigida a crianças seja séria, do ponto de vista da correcção e rigor da informação, e promova a reflexão e o sentido crítico.

A viagem, neste quadro mental, é encarada como uma forma particularmente rica e proveitosa de aprendizagem, que não deve ser desperdiçada. Quando, inesperadamente, encontram na estância turística de luxo do Estoril - "one of the most famous and expensive holiday resorts in Europe" (Wyatt: 99) - os Smith, a família que mora a seu lado em Londres, duas formas de conceber as férias no estrangeiro são mostradas às crianças. Por um lado, o turismo do sol e praia, sem quaisquer interesses de ordem intelectual, que os Smith procuram, 


\section{ESTUDOS/ESSAYS}

e, por outro, a experiência da viagem ao estrangeiro como forma de enriquecimento cultural que os seus pais defendem e promovem:

But I think you know [says Mr. Smith], William and Patience, that people like us who come to Estoril for a holiday are not so much coming to Portugal, to a foreign country, as to a beautiful place with plenty of sunshine and lots of sea. We know it's quite artificial really, that it was built simple as a commercial proposition, that it has no history, no traditions, no real daily life, no mellowness. And frankly we couldn't care less! (Wyatt: 108)

G.H. and I had to admit that, artificial as Estoril was, it had a certain appeal. The Smiths said yes, they liked it. It was, after all, very beautiful and the weather was reliable. We agreed. Although this kind of holiday was not, quite frankly, our cup of tea, we felt there was no reason to be snobbish about it. (Wyatt: 107)

É igualmente por essa razão de busca do autêntico que procuram incutir nos filhos, que o itinerário escolhido não corresponde ao recomendado nos guias de viagem que leram previamente. Recorde-se que ler obras acerca dos lugares a visitar constituía há muito uma prática comum, criando expectativas, opiniões, pré-conceitos. No caso dos viajantes que viriam posteriormente a escrever o seu próprio relato, tal hábito de documentação prévia está, não raro, reflectido na obra, sendo frequentes, ao longo da história da escrita de viagem, os casos de intertextualidade, de apropriação mais ou menos óbvia de ideias e de formulações alheias, ou mesmo de plágio 


\section{descarado. ${ }^{12}$ Tal como Susan Lowndes Marques (1907-1993) ${ }^{13}$ e Ann Bridge (1889-1974), ${ }^{14}$ as autoras de uma outra obra sobre Portugal escrita igualmente por encomenda que fora publicada seis anos antes e alcançara grande sucesso, The Selective Traveller in Portugal (1949) ${ }_{1}^{15}$ também Honor Wyatt preferiu fugir ao previsível, optando por visitar locais pouco conhecidos, fora dos beaten tracks. ${ }^{16}$ Aliás,}

12. Um exemplo é precisamente The Selective Traveller in Portugal (1949). Segundo Ana Vicente, o livro de Susan Lowndes Marques e Ann Bridge foi objecto de plágio em 1956, por parte do Major Osmund Hornby Warne, autor de Portugal (Geneva/Paris/New York/Karlsruhe: Nagel, 1956). O caso resolveu-se em tribunal a favor das autoras. Curiosamente, em Portugal o plágio mereceu a atenção do Secretariado Nacional de Informação (SNI), que comprou quinhentos exemplares para distribuição gratuita, ao passo que o original de Lowndes e Bridge não foi objecto de qualquer interesse ou promoção.

13. Susan Lowndes Marques, escritora e jornalista, filha da romancista Marie Belloc Lowndes (1868-1947), mudou-se para Portugal em virtude de ter contraído matrimónio, em 1938, com o também jornalista Luiz Artur de Oliveira Marques (1898-1976), director do jornal The Anglo-Portuguese News. Figura muito activa da comunidade britânica residente em Lisboa, publicou, para além da obra em parceria com Ann Bridge, outras sobre Portugal: A Practical Guide to Fatima (London: Burns Oates, 1950), Travellers' Guide to Portugal (Londres: Geographia, 1982), Good Food from Spain and Portugal (Londres: Frederick Muller, 1956) e Portugal: A Traveller's Guide (London: Thornton Cox, 1982). Já após a sua morte foi publicado English Art in Portugal (Lisboa: Inapa, 1994), que escreveu com Alice Berkeley.

14. Ann Bridge é o pseudónimo da escritora Mary Ann Dolling O' Malley, casada com o diplomata Owen St. Clair O'Malley (1887-1974), que em 1945 foi nomeado Embaixador britânico em Portugal. Segundo Ana Vicente, foi o agente literário de Ann Bridge quem sugeriu que ela escrevesse um guia sobre Portugal: "Em1947, a Embaixatriz foi contactada pelo seu agente literário. (...) Perguntavam se estava interessada em escrever um novo guia de Portugal, que incluiria não só os locais mais conhecidos, como também zonas raramente visitadas por estrangeiros. Ann Bridge aceitou o desafio com grande entusiasmo, mas pôs uma condição: o livro deveria ser escrito por ela e por uma jovem inglesa, casada com um português, que se chamava Susan Lowndes Marques. Esta até já iniciara um projecto semelhante e era a inglesa que melhor conhecia o país." (Vicente: 224)

15. A obra foi publicada na colecção de livros de viagem "Windows on the World", que surgiu no pós-Segunda Guerra Mundial, um título que também se poderia aplicar à colecção em que se integrou The Young Traveller in Portugal. Segundo Vicente, (226-227) apesar do sucesso obtido no mercado anglo-americano, e de ser um livro favorável a Portugal, não deu que falar no nosso país, nem mereceu a atenção do SNI (Secretariado Nacional de Informação), numa época em que o governo português estava empenhado em promover o turismo por ver nele uma importante actividade económica, geradora de receitas de vulto, e não apenas um veículo de propaganda do país. (cf. Barros: 51) A tradução portuguesa só apareceria em 2009, feita por Jorge Almeida e Pinho, com notas de Ana Vicente (1943-2015), filha de Susan Lowndes Marques, a quem se deve também um livro sobre a sua família: Arcádia: Notícia de uma Família Anglo-Portuguesa. (Algés: Gótica, 2006)

Logo no início da sua obra, Ann Bridge e Susan Lowndes são muito claras quanto ao objectivo de dar um retrato diferente do habitual no seu livro sobre Portugal: "And the aim and purpose of the present book is precisely to provide such an 'anthology' of the varied, unusual and beautiful things to be seen in Portugal." (Bridge and Lowndes: 1) Sobre The Selective Traveller in Portugal, ver: Vicente 2006, Pinho 2009, Alves 2011 e Pereira 2015.

16. O itinerário percorrido por Honor Wyatt e família foi o seguinte: porto de Leixões, Porto, Braga, Chaves, Bragança, Coimbra, Leiria, Batalha, Alcobaça, Nazaré, Caldas da Rainha, Óbidos, Estoril, Cacilhas, Setúbal, Évora, Portimão, Lagos, Sagres, Trafaria, Lisboa e Fátima. A obra inclui, nas páginas 8 e 9, um mapa de Portugal onde surge assinalado o caminho percorrido, com a seguinte legenda: "The thick black line shows the route taken by Patience and William". 
nos já mencionados "Acknowledgments" que abrem a obra, a autora reconhece explicitamente que a leitura de The Selective Traveller in Portugal, um livro focado em particular nas paisagens naturais e no património construído e artístico, privilegiando a vertente estética, foi preciosa (na obra o guia das duas britânicas residentes em Portugal é carinhosamente tratado por "Susan" (Wyatt: 44, 68, 105 e 116) e agradece a Susan Lowndes Marques, sua amiga pessoal, bem como ao marido desta, Luiz Marques (os dois dirigiram durante quase cinquenta anos o jornal inglês publicado em Portugal Anglo-Portuguese News, de que eram proprietários), a ajuda prestada aquando da redacção de The Young Traveller in Portugal. Não que lugares turísticos considerados obrigatórios tenham ficado por ver (como por exemplo, no caso de Lisboa, "one of the loveliest cities in Europe", (Wyatt: 140) a Torre de Belém, o Mosteiro dos Jerónimos, o Museu dos Coches, o Castelo de S. Jorge), mas, por serem sobejamente falados e até já os conhecerem antecipadamente através de fotografias e postais ${ }^{17}$ não merecem descrição demorada e sim apenas curtas referências. Aliás, a autora não fornece, normalmente, descrições pormenorizadas das paisagens e dos lugares por onde passam: o ritmo acelerado da viagem, sempre em deslocação de um sítio para outro e com pouco tempo, dita o ritmo da descrição e dá origem a apontamentos relativamente sucintos. É possível que descrições longas pudessem ser consideradas cansativas para o público-alvo, pois a narradora diz, a certa altura, que os próprios filhos, às tantas, já estavam "sick of looking at things". (Wyatt: 87) Um exemplo flagrante de concisão diz respeito a Sintra, lugar venerado por forasteiros de origem britânica desde há muito e transformado em local de peregrinação romântica, o qual era normalmente objecto de arrebatadas descrições por parte dos viajantes estrangeiros. Neste caso são-lhe apenas dedicadas breves linhas, sem as habituais citações de Childe Harold's Pilgrimage, de Lord Byron - nas palavras de Karen R. Lawrence, um exemplo eloquente do modo como "fictional travel impinges on actual travel" (Lawrence: 25) -, por a descrição ser feita

17. Eis um exemplo desse conhecimento prévio de vistas turísticas de Lisboa amplamente divulgadas, desse déjà $v u$, que ocorre quando se encontram na Trafaria, a que chamam o Estoril dos pobres: "We were watching one of the world's famous pieces of stage-craft: sunset over Lisbon seen from the 'Outra Banda' of the Tagus." (Wyatt: 134) 
pelo jovem William, a quem escapa a magia do lugar e que afirma prosaicamente não terem subido até ao Palácio da Pena por... estar muito calor. (Wyatt: 122)

A Costa da Caparica, outro local considerado imperdível, foi também propositadamente evitado, por ser demasiado frequentado: "All the guide books we had ever read told us that no visitor to Portugal should miss Caparica (...) As G.H. said, it was all enough to make us avoid the place like the plague. (...) We told one another that not seeing Caparica lent a certain distinction to our travels." (Wyatt: 112113) E houve até quem sugerisse à autora, à custa disso, um título para o livro que estava a preparar: "We Missed Caparica". (Wyatt: 113) Sublinhe-se esta vontade deliberada em percorrer um itinerário alternativo aos consagrados pelos guias turísticos que o próprio título da obra, The Young Traveller in Portugal (e também o da colecção em que está integrada, "The Young Traveller Series"), espelha, quando se opta pelo termo traveller e não tourist (o qual ia ganhando conotações negativas). De facto, o primeiro preserva o sentido de uma viagem que foge à crescente massificação e busca antes circuitos que correspondam a gostos e interesses individuais de cariz cultural. A jovem Patience tem consciência de que a viagem que faz em família foge aos padrões do turismo de massas quando, ao tirarem no Templo de Diana, em Évora, fotografias uns dos outros, comenta que se comportaram " 'Just like ordinary tourists!'” (Wyatt: 116)

Em vez da atitude distanciada, arrogante e até fóbica que marcou muitos forasteiros britânicos de visita a Portugal ao longo dos tempos, orgulhosamente convencidos da sua superioridade civilizacional, as personagens de The Young Traveller in Portugal interagem com os naturais das terras que atravessam, visitam as suas casas, entabulam conversa com pessoas das mais variadas classes sociais, incluindo figuras humildes que muitas vezes eram excluídas dos relatos do género, observam os seus costumes, apreciam a gastronomia (memorável) e o modo como é levada a sério pelos portugueses ("Food is not a thing to treat casually"), (Wyat:t 145) aprendem métodos culinários que irão aplicar quando regressarem a casa ("As I helped with the preparations I learned quite a lot of things that I have since applied to my cooking in England"), (Wyatt: 98) adoptam os hábitos das terras por onde passam ("As it was now about tea-time we ordered iced white wine - strange to remember we had once lived in a 
world where one drank tea at tea-time"; (Wyatt: 133) "it was certainly interesting to realize that we too, just like the Portuguese, could make our things clean with cold water and sunshine", (Wyatt: 138) enfim, procuram contactar directamente com a realidade portuguesa quotidiana, demonstrando na sua leitura do Outro-português disponibilidade para aceitar a diferença, empatia e até verdadeiro apreço. O leitor infanto-juvenil de The Young Traveller in Portugal quase não encontra no livro preconceitos ou depreciativos juízos de valor em relação aos portugueses, seus costumes e crenças. Apenas os excessos de devoção e penitência presenciados em Fátima merecem uma nota de condenação. ${ }^{18}$ Porém, a Procissão das Velas é descrita como uma bela e comovente manifestação de fé:

The candlelight seemed the real faith of Fátima, shining with undeniable beauty, just as the reality of a person can shine beautifully through the eyes of a plain face. (...) to all of us, I think, it seemed that the friends we had made in Portugal were here, joining in this act of worship which was surely the fountain-head of the country's faith. (...) They were all there, their faces flickering in the light of faith, their voices raised in singing. We had all met again at the end of the pilgrimage. (Wyatt: 154)

Embora não a mencione na sua obra, Honor Wyatt poderá ter-se documentado mais sobre Fátima também através de uma outra publicação da sua amiga Susan Lowndes Marques, católica, que em 1950 deu à estampa A Practical Guide to Fátima, destinada aos peregrinos ingleses. É precisamente em Fátima que termina o périplo da família inglesa por terras portuguesas e a obra conclui com a nota espiritual acima transcrita. A comparação da viagem realizada pelos protagonistas a uma peregrinação remete o leitor para um tipo de viajante do passado medieval, também ele não movido por razões utilitárias: o peregrino. Curiosamente, vários autores têm estabelecido uma relação entre o moderno turista e o peregrino, como fazem Peter Hulme e Tim Youngs: "In many respects pilgrims were ancestors of modern tourists: a catering industry grew up to look

18. "Unused to such frank and unrestrained show of religious feeling Patience and I, threading our way through the kneeling figures and standing groups, stared about us in a kind of horror." (Wyatt: 151) 
after them, they followed set routes, and the sites they visited were packaged for them." (Hulme and Youngs: 2)

A imagem essencial projectada em The Young Traveller in Portugal é a de um país rural, mas com alguma boa indústria, nomeadamente a de conservas de peixe, (Wyatt: 114) bonitas paisagens, bom clima, excelente comida, vinhos e cigarros baratos ("cheap wine and cigarettes and free sunshine"), (Wyatt: 97) e, sobretudo, com um povo extremamente simpático, hospitaleiro, gentil, bem-educado, (Wyatt: 13, 61) particularmente afectuoso em relação a crianças (Wyatt: 32, 74) e sempre pronto a ajudar os estrangeiros (cruzam-se por várias vezes com estudantes portugueses que falam inglês e se disponibilizam para os ajudar); como é dito na badana da sobrecapa, um país que o leitor ficará com vontade de conhecer: "At the end you will feel you know the Portuguese almost as well as William and Patience, and will be dying to spend your own next holiday in this friendly and exciting country."

Estamos, pois, em presença de uma imagem bastante positiva e até idílica do país como um todo que em muito serve a ideologia do Estado Novo, como observa Valentino José Carvalho do Vale Alves a propósito das narrativas de viagem de autoria britânica:

Apesar da natural predominância turística de determinadas localidades portuguesas, as narrativas turísticas destes livros de viagens escritos por autores britânicos reflectem a imagem de Portugal que foi construída, para consumo interno e externo, pelo Estado Novo e que, em parte, se perpetuou desde então. Esta imagem, que aponta para a existência de uma relação de complementaridade dicotomicamente diferenciadora e unificadora das diversas regiões nacionais, materializa-se nos itinerários de grande parte dos nossos viajantes que concebem Portugal como um país cujos diversos mosaicos culturais (transformados em objectos de consumo turístico) ganham consistência individual a partir da sua integração na composição total. Ou seja, a concepção imagética do Portugal turístico elaborada pelos ideólogos do regime salazarista, de onde se destaca António Ferro, assente numa estetização paisagista (e moral) do país, visando, simultaneamente, realçar as características individuais das diferentes partes e conferir-lhes sentido através da sua integração no todo, tornar-se-á perene. (Alves: 151) 
Também Bridge e Lowndes apresentam no seu livro uma idealização bucólica de Portugal e uma crítica implícita à sociedade mundana e industrial - "Portugal is still, thank goodness, mainly an agricultural country" (Bridge and Lowndes, 1949: 22) ${ }^{19}$-, ilustrando essa exotização da realidade portuguesa, o tipo de reacção que Alain Corbin considera um "contra-valor onírico da civilização técnica". (Corbin: 105) Contudo, apesar de Honor Wyatt representar Portugal como um país acolhedor, pitoresco, exótico, com uma história rica, que vale a pena visitar, a autora não esconde alguns aspectos sombrios da sociedade portuguesa do Estado Novo e o conservadorismo e rigidez dos costumes, nomeadamente no que diz respeito à condição feminina, ainda que não se estenda em comentários. Repara que as mulheres não frequentam os cafés; (Wyatt: 29) que as das classes médias vivem na ociosidade, confinadas ao lar e à condição de esposas e mães, sem direito a exprimir a sua opinião, sem cultivarem interesses intelectuais, (Wyatt: 38) sem autonomia, ao passo que as das classes mais baixas da população trabalham arduamente; (Wyatt: 43) regista o episódio ocorrido na praia do Estoril em que a sua filha foi obrigada por um polícia a ir vestir um fato de banho, por não ser permitido o uso de biquíni, o que por certo permitiu aos potenciais jovens leitores perceber que num outro lugar pode ser vista como falta de pudor ou indecência uma prática que na sociedade de que são oriundos se vai vulgarizando e não causa escândalo; (Wyatt: 108) um outro, passado na praia da Nazaré, em que novamente a sua filha foi admoestada, desta vez por uma mulher do mar, por ter as pernas demasiado à mostra; (Wyatt: 94) constata que as mulheres são arredadas das conversas, provavelmente por se pensar que nada têm a dizer, (Wyatt: 70) o que elas próprias interiorizam; testemunha o modo distante como os rapazes se relacionam com as raparigas e o embaraço de um grupo de estudantes de Bragança quando Patience se lhes dirige directamente; ${ }^{20}$ observa a falta de instrução das mulheres, como os seus temas de conversa se restringem a "clothes, babies,

19. Sobre esta dimensão do guia de Bridge e Lowndes, ver: Pereira, 2015.

20. She was a young woman and in Portugal one does not treat a young woman with familiarity, especially in the presence of her parents. Patience herself, of course, could hardly be expected to share in this decorum. (...) So she actually looked them in the face and spoke without being spoken to. The young men blushed. (Wyatt: 70) 
the climate, and food", (Wyatt: 37) remetendo-se ao silêncio quando inquiridas sobre assuntos de carácter cultural, como por exemplo quando a narradora pergunta à esposa portuguesa de um inglês residente no Porto acerca do estado do teatro em Portugal. ${ }^{21}$ A estes incidentes avulsos juntam-se outros, igualmente significativos, como o que envolve uma lista de filmes que os católicos poderiam ver, lista essa que encontraram afixada na porta de uma igreja, em Évora. A autora, que regista com agrado o asseio da cidade alentejana, anota o facto com ironia, comentando que a limpeza era também de ordem espiritual: "It was a very clean town all the same, glistening and freshened by water sprays. Spiritually clean too. In a church we saw a list of films that Catholics might safely see." (Wyatt: 116)

Tratando-se de um livro para crianças e jovens, a componente política não é desenvolvida, mas não deixa de estar presente, bem como alguma crítica social (veja-se, por exemplo, a denúncia dos intermediários que se enchem de dinheiro à custa da exploração dos camponeses ingénuos, (Wyatt: 62) o que merece ser salientado. Através da narração de episódios ocorridos em certos lugares e da reprodução de conversas travadas com portugueses e ingleses com que se vão cruzando, e que veiculam opiniões sobre o regime vigente, a realidade portuguesa é apresentada sob mais do que um prisma e para lá das aparências. Salazar, por várias vezes mencionado, é definido como um "benign dictator" (Wyatt: 37) e descrito por um inglês residente no Porto como um homem reservado, excepcionalmente inteligente, gentil, católico devoto, com sentido de humor, que não fuma nem bebe, honesto, implacável na aplicação de medidas que considera necessárias, e misterioso, um homem que não se dá a conhecer. Quem conduz a conversa é o marido da narradora, que vai fazendo perguntas ao seu compatriota e obtém dele explicações sobre o modo como Salazar chegou ao poder, a ausência de uma real oposição em Portugal e a supressão de determinadas liberdades, mas também elogios à acção acertada de Salazar no que diz respeito à redução das

21. I wanted to know something about the theatre in Portugal. Were they any good playwrights or actors? The Senhora looked faintly worried and glanced at her husband. 'Peter would know...' And Peter, when asked, supplied the brief information that since it was forbidden to mention either sex or religion in Portuguese plays there was not what one could call a 'living theatre in Portugal'. (Wyatt: 37-38) 
despesas do Estado, ao equilíbrio orçamental, aos cortes no número de funcionários públicos, ao pagamento das dívidas, à captação de investimento estrangeiro e ao desenvolvimento de infra-estruturas (sistemas de irrigação, construção de estradas, pontes, igrejas, hospitais, escolas, casas, restauração de monumentos). ${ }^{22}$ Em Bragança, o já mencionado grupo de estudantes de liceu - a quem esclareceram algumas dúvidas sobre a cultura inglesa, pondo assim em evidência os benefícios mútuos do contacto intercultural ${ }^{23}$ - explicou-lhes o sistema educativo português (que lhes pareceu ter algumas semelhanças com o inglês) e realçou o facto de nos últimos anos, com Salazar no poder, a alfabetização se ter desenvolvido muito entre as gerações mais novas, apesar de grande parte das crianças abandonarem os estudos por volta dos onze anos, o que surpreendeu William e Patience. (Wyatt: 71) Note-se que a informação veiculada acerca deste assunto inclui aspectos relacionados com a ideologia do Estado Novo, ainda que sem ser comentada: " Great stress is laid on giving the children 'the right attitude towards life' and a feeling of pride in their country. Not a pride in physical prowess but in the rightness of the Portuguese way of life. The children belong to the Mocidade Portuguesa, the Portuguese Youth Movement. This is compulsory." (Wyatt: 71) Também o constante barulho de obras em que repararam por onde foram passando lhes transmitiu uma ideia de progresso, de um país "living and lively", (Wyatt: 86) industrioso e em renovação.

As críticas ao regime salazarista ouviram-nas da boca de dois portugueses que conheceram na Trafaria e que lhes falaram do descontentamento silencioso que se vivia em Portugal: "From them we gathered that there are those in Portugal with whom Salazar is not a favourite. Not that they actually said so in so many words." (Wyatt: 136) Reconhecendo embora que Salazar era um bom católico, disseram-lhes que a religião não é tudo e que era preciso progresso industrial para modernizar Portugal. Duas visões então colidem: por um lado, o ponto de vista do português que gostaria de ver o seu país coberto de fábricas, e, por outro, o dos turistas ingleses que temem

\footnotetext{
22. Cf. Wyatt: $35-37$.

23. "'It is being very educational to meet you', said one of the students gravely." (Wyatt: 71)
} 
essa transformação por tal significar o fim de uma realidade pitoresca que lhes agrada, precisamente por o povo viver da agricultura e da pesca, debaixo de um céu livre de poluição: "G.H. and I shuddered at a vision of this lovely smokeless country breaking out in a rash of factories. But we said nothing." (Wyatt: 136)

Em outras narrativas de viagem anglófonas do século XX anteriores a The Young Traveller in Portugal encontramos esta mesma idealização do mundo rural pelo olhar estrangeiro, em tensão com o desejo de progresso dos portugueses, como é o caso do relato Portugal for Two (1931), do norte-americano Alexander Lawton Mackall (1888-1968). Também ele um jornalista, dá voz à oposição entre o seu cansaço em relação à mecanização e à vertigem da vida moderna, longe da natureza, que o leva a tanto apreciar o Portugal rústico, e o sonho dos portugueses de que o seu país se desenvolva industrialmente, pois o pitoresco, só por si, não representa prosperidade económica. Numa visão mais alargada, Mackall apercebe-se também, argutamente, da hipocrisia de muitos turistas que tecem elogios ao exótico e ao pitoresco das sociedades sub-desenvolvidas, convencidos, porém, da superioridade civilizacional da nação de que são originários. ${ }^{24}$

Estas declarações, feitas enquanto quem as proferia olhava receosamente à sua volta, com medo de ser ouvido, deu-lhes a dimensão dos limites à liberdade de expressão impostos em Portugal: " 'But I must be careful what I say.' He lowered his voice like a conspirator. 'Criticism of the régime is not encouraged here. In England you are fortunate. You are free to say exactly what you like where you like.' " (Wyatt: 136) A questão não é, porém, mais desenvolvida, cabendo de seguida ao marido da narradora dar a conhecer aos portugueses que também em Inglaterra existem limitações às liberdades, mas em áreas totalmente diferentes: o facto de os bares fecharem cedo e de as crianças com idade inferior a dezasseis anos não poderem neles entrar, e o não terem a liberdade de planear umas férias ao sol em Inglaterra, sem correrem o risco de ter chuva todos os dias. (Wyatt: 137) Esta nota "humorística" (os termos de comparação são bastante desiguais, pois o que está em causa tem um significado, um valor, e consequências muito distintas) atenua

24. Cf. Castanheira, 2015. 
o peso do diálogo com os portugueses descontentes em relação ao regime de Salazar, mas as crianças inglesas assistiram à conversa e, sendo naturais de um país em que se gozava de muito maior liberdade, terão aprendido que as mesmas não vigoram em todos os lugares e que por detrás da imagem de um Portugal aparentemente tranquilo que eles haviam testemunhado, crescia clandestinamente o clima de contestação social e política.

Todos estes diálogos que lhes permitiram recolher informação pró e contra o regime (como jornalista Honor Wyatt procura, ainda que de forma bastante contida, focar os dois lados da realidade visitada) só foram possíveis porque os forasteiros estudaram o idioma português nos meses anteriores à sua deslocação à Península Ibérica, conscientes de que tal conhecimento, ainda que rudimentar, seria uma chave para o estabelecimento de comunicação directa com o povo com que iriam contactar. Viajar entre culturas é também viajar entre línguas, e essa realidade tem sérias implicações na escrita de viagem, um género por natureza transcultural (e que pode ser entendido como uma forma de tradução e negociação em si mesma ${ }^{25}$ ), como Michael Cronin salienta: "In a multilingual world, language and language difference is an inevitable feature of travel. How travelers deal with the fact of languages other than their own, or radically distinct varieties of their own language, has clear implications for their capacity to engage with or interpret the realities they encounter." (16) A língua portuguesa, enquanto marca identitária do povo visitado, constitui um tópico que atravessa toda a obra, quer sob a forma de abundantes palavras e expressões portuguesas preservadas na sua forma original e destacadas em itálico, símbolo da diferença cultural e reveladoras de conceptualizações particulares que não estão disponíveis na língua materna dos viajantes ingleses, quer sob a forma de pedagógicas explicações do uso correcto do idioma português (por exemplo o emprego dos termos obrigado e obrigada, dependendo do género, questões

25. "In re-presenting other cultures and other natures, then, travel writers 'translate' one place into another, and in doing so constantly rub against the hubris that their own language-game contains the concepts necessary to represent another language-game". (Duncan e Gregory: 4) 
de pronúncia ${ }^{26}$ e formas de tratamento: Wyatt 19, 24 e 31 e 85, respectivamente). Aos jovens leitores é ensinado que é necessário aprender minimamente a língua do país a visitar, o que requer uma preparação prévia, (Wyatt: 23) e que só viajando por um país se adquire um verdadeiro conhecimento da língua nele falada ("the fact is that however much you study a language you never really know what people say till you go to the country itself.") (Wyatt: 31) O lado lúdico da descoberta e aprendizagem de uma nova língua, bem como do processo de tradução, também é salientado, através de episódios divertidos como os que se seguem:

G.H.'s Caldeirada a Fragateira, a kind of fish stew which included eel, skate, and squid with oil and garlic. Caldeirada - we discovered in our dictionary - means kettle-full, so that G.H. had in fact been eating a 'kettle of fish'. Patience enjoyed this bit of translation very much and found several opportunities during the next few days for referring to every difficulty as a pretty Caldeirada a Fragateira. (Wyatt: 110)

I explained. 'Obrigado means obliged. You're not saying "I thank you" but "I'm obliged". "Obliged" agrees with the subject, so in your case it takes the feminine ending " $\mathrm{a}$ ", not he masculine ending " $\mathrm{o}$ " which, by the way, is pronounced, "oo". So William is obrigado and you are obrigada.'

Patience brightened. 'What fun! Let's do it in English too. William, you must always say "thank you" and I shall say "thank ya".'

And this game entertained them till bed-time, which was early that night. (Wyatt: 19)

No final de The Young Traveller in Portugal, completando a função didática da obra, encontramos um índice (Wyatt: 155-158) e um glossário (Wyatt: 158-160) com as palavras e expressões portuguesas que ocorrem ao longo do relato, acompanhadas de transcrições fonéticas aproximadas, o qual pretende ser um auxiliar útil a

26. Como é recorrente nas narrativas de viagem de autoria britânica, a pronúncia portuguesa é considerada difícil: "The fact is that though Portuguese is an easy language on paper its pronunciation is so difficult for English people that even if our vocabulary and grammar are good we are always apt to pronounce an ' $\mathrm{O}$ ' as an ' $\mathrm{O}$ ' instead of as 'OO' and an ' $\mathrm{A}$ ' as ' $\mathrm{A}$ ' instead of ' $\mathrm{Er}^{\prime}$ ', and to make ' $\mathrm{S}$ ' sound like 'S' instead of a mixture of a 'J' and 'SH'." (Wyatt: 24) 
eventuais futuros viajantes em Portugal. ${ }^{27}$

Um grande ensinamento que os protagonistas de The Young Traveller in Portugal e os leitores da obra puderam nela recolher: os estereótipos e os clichés acerca dos países e dos povos, enquanto convenções discursivas, são redutores e não obrigatoriamente verdadeiros, embora a carga mínima de informação que veiculam os tornem aptos à difusão massiva e à fácil fixação na consciência colectiva. Este aspecto da obra permite chamar a atenção para o facto de a escrita de viagem ser um género particularmente adequado aos estudos imagológicos, entendidos, na definição de Manfred Beller e Joep Leerssen, como "the critical analysis of national stereotypes in literature (and in other forms of cultural representation) (...) research in the field of our mental images of the Other and of ourselves". (Beller e Leerssen: xiii) Na verdade, a imagologia - que ganhou especial vitalidade nos anos mais recentes graças, em grande medida, ao trabalho dos dois investigadores atrás citados -, ao debruçar-se sobre os processos de construção das representações caracteriológicas das nações e ao proceder à "desmontagem dos preconceitos na formação das representações literárias", (Simões: 17-18) tem na escrita de viagem um fértil campo de investigação, como sublinha Alfred Meier: "travel writing must be seen as one of the main sources of national typologies". (Meier: 449) O confronto entre o Eu que observa (no caso vertente a viajante-narradora, Honor Wyatt, e a sua família) e o Outro que é observado (Portugal, em The Young Traveller in Portugal), com a sua diferença e a estranheza que consequentemente causa, dá origem a um olhar comparatista (mais ou menos explícito) que gera auto e hetero-imagens discursivas, as quais se enquadram no domínio do que a Psicologia Social designa por estereótipo (de carga positiva ou negativa): "We use the term stereotype for any impression of groups held by anybody regardless of whether the accuracy of that belief is disputed. Stereotypes are impressions of groups held by people. The accuracy of those beliefs may be important in its own right, but it should play no part in the definition of stereotypes". (McGarty, Yzerbyt e Spears: 5) No âmbito dos estudos de imagologia literária,

27. Eis alguns exemplos: Alemtejo (è-len-téshōō); Bacalhau (ba-kèl-yow'ōō); Inez de Castro (i'nes dẻ kas'trōō); Tras-os-Montes (trảz-ōōzh-mon'tezh); Boas noites (bō'èsh noitsh); Fado (fä'dōō); Inglesa (in-glā'zhè); Obrigado (ōō-brē-gà' dōō). 
o estereótipo, com a sua condensação e simplificação de informação relativamente a um grupo, a uma nacionalidade, e enquanto expressão verbal de opiniões, juízos de valor e atitudes que as nações formam e evidenciam ao relacionarem-se entre si, reveste-se de grande importância para a compreensão do modo como as nações se percepcionam e representam mutuamente. ${ }^{28}$ Tratando-se de uma forma literária de mediação cultural em que a representação do estrangeiro tem protagonismo, a narrativa de viagem é especialmente propensa a reflectir a tendência das nações para se atribuirem reciprocamente determinados características/atributos/traços de cariz generalizante, o que, como define Leerssen, constitui em rigor o objecto de estudo da imagologia:

A mayores, y a guisa de resumen, señalaré que la Imagología, es decir, el estudio de las imágenes mentales que subyacen a la representación narrativa y discursiva de las diferencias culturales y de las percepciones interculturales relativas al Otro, no se centra en cualquier forma de representación cultural, sino concretamente en aquellos casos que [a] recurren a caracterizaciones temperamentales y llevan implicadas supuestas psicologías colectivas, y [b] tienen como objeto pretendidos caracteres "nacionales". Como consecuencia de ello, las representaciones de países y sociedades, o de ciudades y regiones, por el mero hecho de describir hechos sociales, geográficos o políticos, no constituyen necesariamente un objeto de estudio para el imagólogo, a menos que estén presentes eventuales elementos ligados a algún tipo de atribución caracterológica. (Leerssen: 138)

Importa também ter em conta, como salientam Álvaro Manuel Machado e Daniel-Henri Pageaux, que "o estereótipo levanta o problema de uma hierarquia de culturas: ele distingue o Eu do Outro e, quase sempre, valoriza o primeiro termo em detrimento do segundo." (Machado e Pageaux: 52) Uma relação de forças desse tipo, em

28. Observe-se que, no campo da imagologia, o termo estereótipo é freqüentemente substituído pelo vocábulo imagotipo, uma vez que, nesta área, trabalha-se com um objeto - a imagem - que, mesmo podendo manter a sua essência inalterada, suas formas e expressões revestem-se normalmente de múltiplas nuances e apresentam-se através de tons cambiantes, ao passo que o estereótipo pressupõe uma estrutura e um significado inalteráveis. (Sousa: 26)

Sobre o conceito de estereótipo e o termo alternativo imagotipo, proposto por Manfred S. Fisher em 1987, ver também: Leerssen, 2007, Simões 2011 e Puga 2014. 
que a cultura observada é vista pela cultura observadora como inferior, é frequente na escrita de viagem britânica sobre Portugal, mas não é essa a atitude que encontramos em The Young Traveller in Portugal. Se de facto, em muitas outras narrativas, está patente, de forma mais ou menos explícita, um sentimento de superioridade em relação à realidade portuguesa visitada - ao falar do Outro, o Eu projecta, necessariamente, uma certa imagem reveladora de Si Mesmo e do seu ponto de vista -, neste caso não estamos perante uma reacção de sobranceria, de hostilidade, e sim de curiosidade, respeito e mesmo de aceitação da diferença, a vários níveis. Ainda que algumas críticas também sejam feitas, por vezes sob a capa da ironia (como sucede no já mencionado episódio relacionado com os filmes), pode dizer-se que a obra exprime, essencialmente, uma ideia de enamoramento por Portugal: ao partirem, este país passa a fazer parte do mapa dos afectos dos protagonistas, os quais levam consigo uma imagem positiva dos portugueses, atribuindo-lhes as já referidas qualidades de simpatia, hospitalidade, boa educação, solicitude, afectividade. Estamos longe aqui dos retratos absolutamente detractores dos portugueses difundidos por narrativas de viagem britânicas dos séculos anteriores, em que estes são pintados não raro como arrogantes, vaidosos, ciumentos, preguiçosos, ignorantes, desonestos, hipócritas, traiçoeiros, vingativos, católicos supersticiosos, de moral dissoluta, destituídos de hábitos de higiene, avessos à inovação, desconfiados em relação aos estrangeiros - traços estes que circularam longamente como uma imagem prototípica dos portugueses.

Procede-se também em The Young Traveller in Portugal a uma desconstrução de estereótipos. Nem sempre encontraram em Portugal o clima quente que esperavam, (Wyatt: 56) tal como em Londres nem sempre perdura o nevoeiro; (Wyatt: 145) tiveram oportunidade de explicar aos portugueses que o tão completo pequeno-almoço inglês não faz afinal parte da sua realidade quotidiana; (Wyatt: 70-71) sentiram frio quando se lavaram nas águas geladas de um rio, apesar de os britânicos serem tidos como resistentes a tudo ("Dash it all, we are British!"); (Wyatt: 56) revelaram-se sonhadores, quebrando assim a ideia-feita de que os ingleses não são românticos; (Wyatt: 30) e foram a prova viva, aos olhos dos portugueses, de que o cliché de que os viajantes vindos do outro lado da Mancha eram todos ricos e ficavam sempre em hotéis não correspondia totalmente à verdade: 
One of the younger women, offering me a handful of shrimps (which I accepted) remarked that she was pleased to find that there were some 'ordinary' English people. 'In Lisbon', she explained, 'we think of the English as nice but rich people who stay in hotels. But you', she looked at my cotton dress, my sandalled, unstockinged feet, 'but you are just like us!'

It was the nicest thing that was said to us in Portugal. (Wyatt: 145)

O tópico da falta de dinheiro (pouco comum nas narrativas de viagem britânicas sobre Portugal) é aflorado por diversas vezes ao longo da obra (por exemplo nas páginas 112 e 116) e, como contra-imagem do inglês rico e opulento, temos a situação destes viajantes com poucos recursos financeiros:

The clerk listened and soon most of the staff was crowding round to hear how the English family was forced by direst poverty to camp on a beach. The English, who were considered so wealthy, who stayed so often at no less a hotel than the luxury Avenida Palace! Sleeping, in near-rags (our clothes were indeed in a shabby state as the glances of the clerks reminded us) on a beach at Trafaria! (Wyatt: 141)

Fica a sugestão de que é preciso constatar in loco como os povos vivem, e julgar com os próprios olhos as diferenças de que as identidades sociais e culturais se constroem, não confundindo os estereótipos com a realidade.

Robert Wyatt ("William") e Prudence Wyatt ("Patience") guardariam para sempre boas recordações da viagem feita a Portugal quando eram crianças. Sabemo-lo pela biografia autorizada do primeiro, publicada em 2014, onde se fazem ouvir as vozes de ambos. Prudence relembra o carácter aventureiro e o improviso da experiência então vivida, sem terem ao seu dispor carro próprio ou sequer uma tenda:

Honor researched the Portugal book in 1953, travelling on a shoestring 
with eight-year-old Robert ${ }^{29}$ and his older half-sister Prue. 'We travelled by bus a lot of the time,' remembers Prue, 'although sometimes we were lucky enough to get a lift in a truck or cart or something like that. We slept wherever, in blankets that my mother had stitched up - they were old army blankets of George's. We were just camping, but we had no tent. We'd sleep under the stars: in woods, in forests, wherever we could.' (O' Dair: 24)

Já Robert se revela bastante emotivo quando recorda esses tempos. ${ }^{30}$ Reconhecendo hoje que Portugal, nessa época, era um país bastante pobre, não deixa de confessar que aos olhos da criança que então era tudo lhe pareceu maravilhoso: "Robert also remembers the trip with affection. 'I absolutely loved the place', he recalls. 'Dirt poor', I now realize, but magical to me at the time.'” (O' Dair: 24) E um seu amigo, mais adiante no livro, narra um curto episódio que sublinha a pobreza do Portugal visitado: "Wyatt is a worrier. When in Portugal with Honor and Prue, he had been so embarassed at the poverty he witnessed that for a period he refused to wear any shoes." (O' Dair: 37)

Em The Young Traveller in Portugal a questão da pobreza não é muito aprofundada mas está presente, umas vezes de forma mais subentendida, outras mais evidente (por exemplo através das várias referências a mendigos), sobretudo quando são relatadas situações relacionadas com crianças que William e Patience testemunharam, o que por certo se prende com o facto de a obra se dirigir ao público infanto-juvenil e, como tal, privilegiar aspectos de valor educativo para os mais novos:

On the edge of the town [Braga] we found a big square of sweet rather dirty little houses whitewashed pink (if you know what I mean!) with white edges to the doors and windows. People were leaning out of the windows screaming to other people and there were a lot of dirty little children about. (The children do seem to be rather dirty and William says he feels horribly superior being clean...) (Wyatt: 46)

29. Na obra, o filho surge como um rapaz de doze anos, reduzindo-se assim a diferemça de idade entre os irmãos e tornando mais verosímeis os comentários e observações do rapaz.

30. Tão duradouras foram as memórias desses dias felizes que o EP que Wyatt lançou em 1992, A Short Break, tem na capa uma foto sua em Portugal, tirada aquando da viagem feita em criança, em 1953. 
E, no Alentejo: "We asked the children if they went to school. No. According to law all Portuguese children of school age should go to school, but, as G.H. said, they could hardly walk to Evora from here every day and presumably they were not rich enough to afford a taxi like us." (Wyatt: 119) Por serem crianças, contudo, a pobreza e falta de meios não os impressiona tanto quanto aos adultos, como sublinha a narradora a propósito das poucas condições para acolher as multidões de peregrinos que acorriam ao santuário de Fátima: "Patiente and William, however, were not worried. Like young people the world over they amused themselves with small homely things among all this strangely impersonal flow of humanity, far removed, indeed, in place and experience from anything they had ever known before." (Wyatt: 150)

São muitos os episódios em que William e Patience se vêem diante de uma realidade que lhes possibilita fazer uma comparação entre as características, os costumes, os níveis de desenvolvimento do seu lugar de origem (a Inglaterra) e os do país visitado - vejam-se, a título ilustrativo, as comparações estabelecidas entre o clima em Portugal e em Inglaterra, (Wyatt: 85) a condição da mulher portuguesa e a inglesa, esta muito mais activa e culta e gozando de bem mais autonomia, (Wyatt: 38-39) os tratamentos dados às crianças, nomeadamente o facto de as portuguesas irem para a cama muito mais tarde e o hábito de lhes ser dado a beber vinho diluído em água desde tenra idade, (Wyatt: 32,18) ou as diferenças a nível da execução das tarefas domésticas nas casas de classe média, em Portugal essencialmente a cargo de criadas que auferiam baixos salários (Wyatt: 33-34) -, com o consequente processo de auto-identificação enquanto ingleses através da diferenciação em relação aos portuugeses. Além disso, ao percorrerem Portugal os jovens puderam perceber que se eles eram forasteiros observadores de uma sociedade para eles desconhecida, também eram observados com curiosidade e interesse pelos naturais do país: "Windows opened as we passed and heads appeared." (Wyatt: 96)

Hoje, na era da globalização, a mobilidade de crianças e jovens é intensa e a sua experiência do estrangeiro muitíssimo frequente, mas à data da publicação de The Young Traveller in Portugal essa prática era um fenómeno recente, porquanto até ao século XX a viagem ao estrangeiro estivera praticamente reservada aos adultos. Isso 
mesmo diz Honor Wyatt numa outra obra que viria a publicar em 1961, Young People Abroad, em que reúne um conjunto sistematizado de conselhos práticos e recomendações úteis para organizar viagens de jovens até aos vinte anos de idade ao estrangeiro: ${ }^{31}$

This is a situation which, fifty or so years ago, did not often occur in the lives of people under twenty, whether British or of any other nationality. True, there were, even then, a few moneyed parents all over Europe who contrived to send their daughters to be 'finished' in Switzerland; there were also some enterprising British families who occasionaly chose to holiday in Belgium rather than Bournemouth; some pioneering French, German or Spanish families who spent the summer season in Devonshire rather than Britanny, the Black Forest or the Costa Brava. And there was a sprinkling of students with the initiative to make their way to foreign universities. But these were exceptions to the rule that reserved foreign travel for Adults Only.

There were, apart from expense, various reasons for this. For one thing it was felt that young people were incapable of 'appreciating' the experience of travel. (...) But even more important - to the English at least - were the appalling, though often imaginary hazards of travelling abroad. Hazards to which persons of tender years could not possibly be exposed. (...) more alarming even than foreign water and foreign food, were foreigners! Some of these, of course, were charming, but one could never be sure. After all, they had not had the inestimable advantages of an upbringing such as one had had in one's own country and quite a number of them, though this was hard to believe, did not speak a word of one's own language.

So $(\ldots)$ the young members of the family were left at home, in the safety of nursery and classroom, on a diet of stew and rice pudding. And other Europeans were, in the main, equally unadventurous.

Today the picture of foreign travel has changed, thanks in part to the two wars, those ill winds which have blown at least some good of understanding and friendship through the corridors of Europe. Most of us, both

31. Num breve texto que antecede o frontispício da obra, a editora promove a autora apresentando-a como uma pessoa com um bom conhecimento da matéria de que fala: "Honor Wyatt is the mother of three internationally minded children and since they were very young indeed she has found herself waving goodbye to them from platforms and quaysides as they set off to spend their holidays in other countries." 
children and adults, travel much more than we used to. Indeed, travel has become such a thriving industry that it sometimes seems that almost all of us have been almost everywhere. (Wyatt, 1961: 9-10)

Esse manual, em que defende a importância da viagem a outros países para a educação dos jovens, constitui um interessante complemento à leitura do livro The Young Traveller in Portugal. Com o volume que integrou a colecção "The Young Traveller Series", a autora pretendeu ensinar às crianças e jovens como a viagem é uma experiência rica, formativa, transformadora, que proporciona não apenas conhecimento sobre o mundo exterior mas também sobre si próprio. ${ }^{32}$ Ao sair da zona de conforto da língua-mãe e ao expor-se à diferença cultural, o viajante sujeita-se a uma experiência que põe à prova a sua capacidade de adaptação e resistência, a sua coragem até, por vezes. Em The Young Traveller in Portugal, Patience e William nunca passam por situações de risco, mas sair da rotina do seu quotidiano inglês tem uma dimensão de aventura e de desafio pessoal que desde sempre esteve associada à viagem. Para além disso, é uma oportunidade para perceberem que a Europa não é um espaço homogéneo, antes pelo contrário, é feito de diferenças e especificidades - aquilo a que Glenn Hooper e Tim Youngs chamam "Europe and its various Others". (Hooper e Youngs: 1) Sobretudo, reforça-se a visão de que a experiência do estrangeiro pode, e deve, contribuir para promover a tolerância, a compreensão e a amizade entre os povos e fomentar o anti-etnocentrismo.

32. "Travel abroad or to places different than our own, affects identity, for we often define ourselves in reaction to others. Certainly with new experiences and meeting new people, our world vison changes, but we also tend to define ourselves against the other." (Roberson: xviii) 


\section{ESTUDOS/ESSAYS}

\section{Obras Citadas}

\section{I) Fontes primárias}

Wyatt, Honor. The Young Traveller in Portugal. London: Phoenix House Ltd, 1955.

\section{II) Fontes secundárias}

Abaitua, Matthew de. The Art of Camping. The History and Practice of Sleeping Under the Stars. London: Penguin Books, 2012.

Alves, Valentino José Carvalho do Vale. O Olhar das Palavras do Turista Britânico: Representações de Portugal nos Livros de Viagens, 1950-2000. Tese de Doutoramento apresentada à Faculdade de Letras e Faculdade de Ciências do Desporto e Educação Física da Universidade de Coimbra. Universidade de Coimbra, 2011.

Barros, Vera Gouveia. Turismo em Portugal. Lisboa: Fundação Francisco Manuel dos Santos, 2016.

Batten, Charles. Plesurable Instruction: Form and Convention in Eighteenth-Century Travel Literature. Berkeley: University of California Press, 1978.

Beller, Manfred. "Stereotype." Imagology. The Cultural Construction and Literary Representation of National Characters: A Critical Survey. Edited by Manfred Beller and Joep Leerssen. Amsterdam and New York: Rodopi, 2007. 429-434.

--- e Joep Leerssen (eds.) Imagology. The Cultural Construction and Literary Representation of National Characters: A Critical Survey. Amsterdam and New York: Rodopi, 2007.

Borm, Jan. "Defining Travel: On the Travel Book, Travel Writing and Terminology". Perspectives on Travel Writing. Edited by Glenn Hooper and Tim Youngs. Aldershot: Ashgate, 2004. 13-26.

Bridge, Ann e Susan Lowndes. Duas Inglesas em Portugal. Uma Viagem pelo País nos Anos 40. Tradução de Jorge Almeida e Pinho. Matosinhos: Quidnovi, 2008.

---. The Selective Traveller in Portugal. London: Evans Brothers Limited, 1949.

Butor, Michel. "Travel and Writing". Defining Travel: Diverse Visions. Edited by Susan L. Roberson. Jackson, MS: University Press of Mississippi, 2001. 69-87.

Castanheira, Maria Zulmira. "Here-and-there-ing in Portugal in 1929: The Perspective of an American "impression-gatherer". Interdisciplinary Journal of Portuguese Diaspora Studies. Editors Irene Maria F. Blayer e Dulce Maria Scott. Vol. 4.2. Special Issue: Neither Here nor There, Yet Both: The Luso-American Experience. Guest Editors: Margarida Vale de Gato, Teresa Alves, Rui Azevedo, Teresa Cid, and Isabel O. Martins. Vol. 4.2. (2015): 312-333. 


\section{REAP/JAPS 26}

Corbin, Alain. História dos Tempos Livres: O Advento do Prazer. Tradução de Telma Costa. Lisboa: Teorema, 2001.

Cronin, Michael. "Speech Acts: Language, Mobility, and Place". Travel and Ethics: Theory and Practice. Edited by Corinne Fowler, Charles Forsdick, and Ludmilla Kostova. New York and London: Routledge, 2014. 16-30.

Duncan, James e Derek Gregory (eds.) Writes of Passage: Reading Travel Writing. London and New York: Routledge, 1999.

Fussell, Paul. Abroad: British Literary Traveling Between the Wars. Oxford and New York: Oxford University Press, 1980.

Holland, Patrick and Graham Huggan. Tourists with Typewriters: Critical Reflections on Contemporary Travel Writing. Ann Arbor: University of Michigan Press, 1998.

Hooper, Glenn e Tim Youngs. "Introduction". Perspectives on Travel Writing. Edited by Glenn Hooper and Tim Youngs. Aldershot: Ashgate, 2004. 1-11.

Hulme, Peter e Tim Youngs. "Introduction". The Cambridge Companion to Travel Writing. Edited by Peter Hulme and Tim Youngs. Cambridge: Cambridge University Press, 2002.

Lawrence, Karen R. Penelope Voyages: Women and Travel in the British Literary Tradition. Ithaca and London: Cornell University Press, 1994.

Leerssen, Joep. "Imágenes nodales (el ejemplo de Carmen)". Imagologías Ibéricas: construyendo la imagen del otro peninsular. Coordinadoras: María Jesús Fernández García y Maria Luísa Leal. Mérida: Gobierno de Extremadura/ Dirección General de Inversiones y Acción Exterior/Gabinete de Iniciativas Transfronterizas, 2012. 137-147.

Löfgren, Orvar. On Holiday: A History of Vacationing. Berkeley/Los Angeles/London: University of California Press, 1999.

Lowndes, Susan. A Practical Guide to Fatima. London: Burns Oates, 1950.

Machado, Álvaro Manuel e Daniel-Henri Pageaux. Da Literatura Comparada à Teoria da Literatura. $2^{a}$ edição, revista e aumentada. Lisboa: Editorial Presença, 2001.

McGarty, Craig, Vincent Y. Yzerbyt e Russell Spears. "Social, Cultural and Cognitive Factors in Stereotype Formation". Stereotypes as Explanations: The Formation of Meaningful Beliefs about Social Groups. Edited by Craig McGarty, Vincent Y. Yzerbyt and Russell Spears. Cambridge: Cambridge University Press, 2002.

Meier, Alfred. "Travel Writing". Imagology. The Cultural Construction and Literary Representation of National Characters: A Critical Survey. Edited by Manfred Beller and Joep Leerssen. Amsterdam and New York: Rodopi, 2007. 446-450.

O'Dair, Marcus. Different Every Time. The Authorised Biography of Robert Wyatt. London: Serpent's Tail. Kindle Edition, 2014.

Pereira, Teresa. " "The Enchantments of the Portuguese Countryside": Escrita de Viagens e Propaganda Turística". Revista de Estudos Anglo-Portugueses 24 (2015): 235-246. 


\section{ESTUDOS/ESSAYS}

Pinho, Jorge. " 'The Selective Traveller in Portugal': Anacronismos e Peculiaridades de um Olhar sobre Portugal". Via Panorâmica, Série 2, nº 2 (2009): 101-128.

Puga, Rogério Miguel. Imagologia e Mitos Nacionais. O Episódio dos Doze de Inglaterra na Literatura Portuguesa (c. 1550-1902) e o Nacionalismo (Colonial) de Teófilo Braga. Casal de Cambra: Caleidoscópio, 2014.

Roberson, Susan L. "Defining Travel: an Introduction". Defining Travel: Diverse Visions. Edited by Susan L. Roberson. Jackson, MS: University Press of Mississippi, 2001. xi-xxvi.

Simões, Maria João (coord.) Imagotipos Literários: Processos de (Des)Configuração na Imagologia Literária. Coimbra: Centro de Literatura Portuguesa/Faculdade de Letras da Universidade de Coimbra, 2011.

Sousa, Celeste H. M. Ribeiro de. Do Cá e do Lá: Introdução à Imagologia. São Paulo: Associação Editorial Humanitas, 2004.

Vicente, Ana. Arcádia: Notícia de uma Família Anglo-Portuguesa. Algés: Gótica, 2006.

Youngs, Tim. The Cambridge Introduction to Travel Writing. Cambridge: Cambridge University press, 2013.

Wyatt, Honor. Young People Abroad. London: Hurst \& Blackett, 1961. 